\title{
Nematode-microbe complexes in soils replanted with apple
}

\author{
Xorla Kanfra ${ }^{1}$, Andreas Wrede ${ }^{2}$, Julia Moll ${ }^{3}$ and Holger Heuer 1,* \\ 1 Institute for Epidemiology and Pathogen Diagnostics, Julius Kühn Institute (JKI) - Federal Research Centre \\ for Cultivated Plants, Braunschweig, Germany; xorla.kanfra@julius-kuehn.de \\ 2 Department of Horticulture, Landwirtschaftskammer Schleswig-Holstein, Ellerhoop, Germany; \\ awrede@lksh.de \\ 3 Department of Soil Ecology, Helmholtz Centre for Environmental Research - UFZ, Halle (Saale), Germany; \\ julia.moll@ufz.de \\ * Correspondence: holger.heuer@kjulius-kuehn.de
}

\begin{abstract}
Apple replant disease is a severe problem in orchards and tree nurseries. Evidence for the involvement of a nematode-microbe disease complex was reported. To search for this complex, plots with a history of apple replanting, and control plots cultivated for the first time with apple were sampled in two fields in two years. Shoot weight drastically decreased with each replanting. Nematodes were extracted from soil samples by floatation-centrifugation, washed on a $20 \mu \mathrm{m}$-sieve, and used for DNA extraction. Nematode communities and co-extracted fungi and bacteria were analyzed by high-throughput sequencing of amplified ribosomal fragments. The nematode community and co-extracted fungal and bacterial communities significantly differed between replanted and control plots. Free-living nematodes of the genera Aphelenchus, Cephalenchus, and an unidentified Dorylaimida were associated with replanted plots, as indicated by linear discriminant analysis effect size. Among the co-extracted fungi and bacteria, Mortierella was most indicative of replanting. Some genera, mostly Rhabditis, indicated healthy control plots. Isolating and investigating the putative disease complexes will help to understand and alleviate stress-induced root damage of apple in replanted soil.
\end{abstract}

Keywords: replant disease; Malus; free-living nematodes; bacteria; fungi; rhizosphere; nematodemicrobe association; disease complex; metabarcoding; nematode community

\section{Introduction}

Continuous monoculture is commonly associated with intensive agricultural production and may result in negative plant-soil feedbacks leading to yield decline of crops [1]. Replant disease was described as the phenomenon that soil gradually looses its capacity to support growth of a specific plant after replanting without any known pathogen causing the decline [8,9]. For apple, the phenomenon has been termed specific sickness [2] or specific apple replant disease (ARD) [3] to distinguish it from root damage by the endoparasitic nematode Pratylenchus penetrans. Affected plants show significantly reduced shoot growth, root cell necrosis and patchy blackening of root cells, impaired root hair development, and low cell vitality which may lead to root death [4]. Fruit yield and quality are significantly reduced [5]. ARD is a worldwide phenomenon affecting various apple-growing regions yet the causes are still not clear [6-8].

Mitigating measures such as soil pasteurization or fumigation significantly improved the growth of apple plants which gives evidence that the disease is caused by biotic factors [9]. Accumulation of phenolic compounds or phytotoxins in disease-affected roots has been discussed to play a role in the disease $[10,11]$. Recently, a transcriptomic analysis of the molecular responses of apple plants to ARD soils showed peculiar defense reactions to biotic stress, especially up-regulation of genes for phytoalexin synthesis but failed to point to the specific biotic origin of the disease [12]. Depending on the study, various biotic agents including the oomycetes Pythium and Phytophthora, the fungi Cylindrocarpon, Fusarium and Rhizoctonia, or bacteria of the genera Bacillus, Pseudomonas, Actinobacteria 
have been implicated with ARD-related growth depression [5,13-15]. The endoparasitic nematode $P$. penetrans was frequently found in affected orchards, but the abundance was often below damage thresholds or did not correlate with disease symptoms $[10,16]$. To identify biotic causes outside the root, high throughput sequencing data of bacterial and fungal communities in ARD-affected and healthy soils were compared [17]. Significant differences were revealed, including elevated levels of nematode-associated bacteria and fungi in ARD soil, but particular causative agents have not been identified yet. Extracellular compounds released by fungi in the apple rhizosphere were shown to affect apple roots $[14,18]$. Thus, biotic interactions in the rhizosphere of apple plants may lead to the external production of deleterious compounds that trigger ARD. The involvement of nematodes in such interactions has not been investigated so far. Some species of soil nematodes are involved in interactions with microbes that affect higher organisms as insects [19], livestock [20], or plants [21,22].

Free-living nematodes in soil include bacterivores, fungivores, and root feeders. In contrast to endoparasitic nematodes, they are not well studied. Evidence is mounting that nematodes contribute to ARD. Heating to $50^{\circ} \mathrm{C}$ [23], planting of Tagetes [24,25], or application of nematicides [26,27] were treatments of ARD soils that targeted nematodes and ameliorated the disease. Recently, we showed that the nematode fraction extracted from ARD soil induced root symptoms typical for ARD, like reduced weight, increased levels of phenolic compounds and phytoalexins, and browning [28]. We separated nematodes and microbes from ARD soils (replanted) or control soils (first time planted with apple) from plots of the same field and inoculated the fractions in combinations or singly to ARDsusceptible apple rootstocks. The microbial fraction from ARD soil and control soil enhanced the disease symptoms when added to the nematodes, but had only minor effects without the nematodes. The nematode fractions were thoroughly washed with sterile water but contained the microbes that were strongly associated with the nematode bodies. As we did not detect significant numbers of plant-parasitic nematodes in the ARD soils and not more than in the control soils, we concluded that particular free-living nematodes in association with certain soil microbes induced the disease symptoms. When ARD soils were pre-cultivated with Tagetes, the extracted nematode fraction did not induce ARD anymore [25].

The objective of this study was to compare nematode communities and nematodeassociated microbial communities extracted from ARD plots and control plots in two fields and two years. The study was done with soils from two experimental fields, where plots were either frequently replanted or planted the first time with apple rootstocks, and known pathogens of apple did not play a significant role [24,28-31]. We hypothesized that differences in the community structure of free-living nematodes and the nematode-associated fungi or bacteria between ARD and healthy soils will reveal putative disease complexes that are associated with the induction of ARD symptoms. We used high-throughput amplicon sequencing to characterize the nematode and nematode-associated microbial communities.

\section{Materials and Methods}

\subsection{Field soil sample collection and nematode extraction}

Soils from ARD reference field sites Heidgraben $\left(53.6992^{\circ} \mathrm{N} 9.6832^{\circ} \mathrm{E}\right)$ and Ellerhoop $\left(53.7143^{\circ} \mathrm{N} 9.7701^{\circ} \mathrm{E}\right)$ both of which were located in the tree nursery area around Pinneberg, Germany, were used for this study. At Heidgraben, an Entic Podzol (according to WRB 2015) had developed from aeolian sand. The soil in Ellerhoop was classified as an Endostagnic Luvisol from glacial till. On the field plots, the apple rootstock 'Bittenfelder Sämling' was repeatedly planted and uprooted at the Heidgraben site (planting of ARD plots in 2009, 2010, 2012, 2014, 2016; uprooting in 2009, 2011, 2013, 2015, 2017) and at the Ellerhoop site (planting of ARD plots in 2009, 2011, 2013, 2015, 2017, 2019; uprooting in $2010,2012,2014,2016,2018,2020$ ) in four randomly arranged plots interspersed with four 
control plots covered with grass [11,29,32]. At each uprooting, the shoot fresh mass was determined for each plot. Before soil sampling was started, the grass was removed from thw control plots and apple was planted to get a non-replanted control. In Heidgraben, the soil samplings were done in April 2016 (H1) and in April 2017 (H4). In Ellerhoop, we took soil samples in November 2017 (E2) and in April 2018 (E3). Soil samples of each plot were taken at a depth of 0-30 cm from the apple root zone of three individual plants in a zigzag pattern. These constituted 24 samples from each site, sampled at two different time points equaling 96 soil samples in total. Root fresh mass was recorded for samplings E3 and H4. The soil samples were stored at $4^{\circ} \mathrm{C}$ for two weeks before nematode extraction. Nematodes were extracted from $250 \mathrm{ml}$ portions of the soils by centrifugal floatation using $\mathrm{MgSO}_{4}$ at 1.18 specific density [33]. Nematodes were collected on a $20-\mu \mathrm{m}$ sieve, thoroughly washed with sterile water, transferred to $50 \mathrm{ml}$ tubes with sterile water, pelleted by centrifugation at $4000 \mathrm{~g}$ for $20 \mathrm{~min}$. The pellet was frozen at $-20^{\circ} \mathrm{C}$ until DNA extraction.

\subsection{Characterization of the nematode diversity}

Total DNA from each soil nematode pellet was extracted using the FastPrep FP120 bead beating system for $30 \mathrm{~s}$ at high speed for cell lysis of nematodes and associated microbes, and the FastDNA SPIN Kit for Soil (MP Biomedicals, Eschwege, Germany) as described by the manufacturer. To characterize the nematode diversity, the primer SSU18SF01 GATCAGGGTTCGACTCCGGAGA (this study) targeting the 18S rRNA genes of nematodes together with the D2B primer AGTTTCCTCTGGCTTCGTCCTGC [34], which targets the D2/D3 expansion segment of the 28S rRNA gene, were used to amplify about $4 \mathrm{~kb}$ of the rRNA cistron in a PCR reaction mix containing $10 \mu \mathrm{l}$ of 5x Q5 reaction buffer (New England Biolabs), $7.5 \mu \mathrm{l} 2 \mathrm{mM}$ dNTP, $2.5 \mu 12 \mathrm{mg} / \mathrm{ml}$ BSA, $10 \mu \mathrm{l}$ Q5 High GC Enhancer (New England Biolabs), $0.5 \mu \mathrm{l} 2 \mathrm{U} / \mathrm{ml}$ Q5 High-Fidelity DNA Polymerase (New England Biolabs), and $2.5 \mu \mathrm{l}$ of each primer $(10 \mu \mathrm{M})$. Template DNA and water were added to give a final volume of $50 \mu$ for each sample. The PCR was carried out using the following cycling conditions: the thermocycler block was heated for $1 \mathrm{~min}$ followed by an initial denaturation of $5 \mathrm{~min}$ at $95^{\circ} \mathrm{C}, 20$ cycles of $\left(95^{\circ} \mathrm{C}\right.$ for $15 \mathrm{~s} ; 54^{\circ} \mathrm{C}$ for $30 \mathrm{~s} ; 68^{\circ} \mathrm{C}$ for $2 \mathrm{~min}$ ) and a final extension at $68^{\circ} \mathrm{C}$ for $4 \mathrm{~min}$. In a nested PCR, around 362 bp of $18 \mathrm{~S}$ rDNA was amplified from the first PCR products using the forward primer NF1 CGTATCGCCTCCCTCGCGCCATCAG and the reverse primer 18Sr2b CTATGCGCCTTGCCAGCCCGCTCAG [35], with Illumina 5'-overhang TCGTCGGCAGCGTCAGATGTGTATAAGAGACAG or GTCTCGTGGGCTCGGAGATGTGTATAAGAGACAG, respectively. PCR reactions of $50 \mu \mathrm{l}$ contained $10 \mu \mathrm{l}$ of 5x GoTaq Flexi buffer (Promega, Mannheim, Germany), $7.5 \mu \mathrm{l} 25 \mathrm{mM} \mathrm{MgCl}$, $5 \mu \mathrm{l}$ of $2 \mathrm{mM}$ dNTP each, 1 $\mu \mathrm{l}$ of each $10 \mu \mathrm{M}$ primer solution, $2.5 \mu \mathrm{l}$ of $2 \mathrm{mg} / \mathrm{ml} \mathrm{BSA}, 4 \mu \mathrm{l}$ of $50 \%$ acetamide, $0.4 \mu \mathrm{l}$ of $5 \mathrm{U} / \mu \mathrm{l}$ GoTaq DNA polymerase (Promega). The following PCR cycler condition was used: initial denaturation of $5 \mathrm{~min}$ at $94^{\circ} \mathrm{C}, 25$ cycles of $\left(94^{\circ} \mathrm{C}\right.$ for $45 \mathrm{~s} ; 54^{\circ} \mathrm{C}$ for $30 \mathrm{~s} ; 72^{\circ} \mathrm{C}$ for 1 $\mathrm{min}$ ), and a final extension of $10 \mathrm{~min}$ at $72^{\circ} \mathrm{C}$. The resulting PCR product was purified using the High Pure PCR Purification kit (Roche Diagnostics GmbH) following the manufacturer's instructions. Barcoded amplicon sequencing of the 18S rRNA genes was done by 2 x 300 bp paired-end high-throughput sequencing (MiSeq Reagent kit v3) on an Illumina MiSeq platform (Illumina, San Diego, CA, United States) at the Department of Soil Ecology of the Helmholtz Centre for Environmental Research - UFZ, Halle, Germany [36].

\subsection{Characterization of the nematode-associated microbial diversity}

The fungal community associated with the extracted nematodes was amplified using the primers gITS7 and ITS4 targeting the ITS2 region [37]. PCR was performed in a reaction mixture of $50 \mu \mathrm{l}$ consisting of $10 \mu \mathrm{l}$ of 5x GoTaq Flexi buffer (Promega, Mannheim, Germany), $5 \mu \mathrm{l}$ of $25 \mathrm{mM} \mathrm{MgCl}, 5 \mu \mathrm{l}$ of $2 \mathrm{mM}$ dNTP, $2.5 \mu \mathrm{l}$ of $2 \mathrm{mg} / \mathrm{ml}$ BSA, $1 \mu \mathrm{l}$ of each primer $(10 \mu \mathrm{M}), 1 \mu \mathrm{l}$ of $5 \mathrm{U} / \mu \mathrm{l}$ GoTaq polymerase (Promega), and $1 \mu \mathrm{l}$ of nematode community DNA. The following PCR cycler condition was used: initial denaturing of $5 \mathrm{~min}$ at $94^{\circ} \mathrm{C}$, followed by 30 cycles of $\left(94^{\circ} \mathrm{C}\right.$ for $30 \mathrm{~s}, 56^{\circ} \mathrm{C}$ for $30 \mathrm{~s}, 72^{\circ} \mathrm{C}$ for $\left.1 \mathrm{~min}\right)$ and final elongation at $72^{\circ} \mathrm{C}$ for $5 \mathrm{~min}$. To characterize the bacterial diversity associated with the 
extracted nematodes, the V3-V4 regions of 16S rRNA genes were amplified using the primers 341F [38] and 806R [39] in a $25 \mu \mathrm{l}$ reaction volume containing $2.5 \mu 1$ 10x of standard reaction buffer (NEB), $0.125 \mu \mathrm{l}$ of $5 \mathrm{U} / \mu \mathrm{l}$ NEB HotStart Taq polymerase, $2.5 \mu \mathrm{l}$ of $2 \mathrm{mM}$ $\mathrm{dNTP}, 1 \mu \mathrm{l}$ of $2.5 \mathrm{mM} \mathrm{MgCl}, 2.5 \mu \mathrm{l}$ of $2 \mathrm{mg} / \mathrm{ml} \mathrm{BSA}, 1 \mu \mathrm{l}$ of each primer $(10 \mu \mathrm{M})$ and $1 \mu \mathrm{l}$ of nematode community DNA. The following temperature steps were applied: $2 \mathrm{~min}$ at $94{ }^{\circ} \mathrm{C}, 30$ cycles of $20 \mathrm{~s}$ at $94^{\circ} \mathrm{C}, 20 \mathrm{~s}$ at $56^{\circ} \mathrm{C}, 40 \mathrm{~s}$ at $72{ }^{\circ} \mathrm{C}$, followed by a final elongation for $5 \mathrm{~min}$ at $72{ }^{\circ} \mathrm{C}$. Amplicon sequencing of the ITS2 or $16 \mathrm{~S}$ rRNA genes was done by $2 \mathrm{x}$ $250 \mathrm{bp}$ paired-end high-throughput sequencing on an Illumina HiSeq 2500 platform by Novogene (Cambridge, UK).

\subsection{Sequence analysis}

The 18S rRNA, ITS, or 16S rRNA sequence demultiplexing was done using the MiSeq Controller Software and diversity spacers were trimmed using Biopieces (www.biopieces.org). The sequence reads for nematodes and nematode-associated bacteria were processed using USEARCH (v11.0.667). Raw reads were processed using the protocol established in the USEARCH pipeline followed by OTU clustering using UPARSE [40]. The nematode sequence read preparation and processing included paired-end merging with an overlapping minimum read length of 10 base pairs, filtering of low-quality sequences, and dereplication to find unique sequences following default settings. OTU clustering and chimera removal was performed at a 97\% identity threshold via the cluster_otu command implemented in the UPARSE algorithm. BlastN assigned taxonomic affiliations for the nematodes were done against the Silva SSU 138 database [41]. Processing of the bacteria sequence reads included paired-end merging with an overlapping minimum read length of 10 base pairs and minimum merge length of $400 \mathrm{bp}$. Filtering of low-quality sequences, and dereplication to find unique sequences was done following default settings. OTU clustering and chimera removal was performed at a $97 \%$ identity threshold via the cluster_otu command implemented in the UPARSE algorithm. OTU sequences were taxonomically assigned by BlastN against the Silva SSU 138 database [41]. For the fungi reads, overlapping regions within paired-end reads were aligned to generate "contigs" by PANDAseq using default settings [42]. Taxonomic affiliations were assigned by BlastN against the UNITE database version 8.3 [43] with the Expect Value of 0.001, which was performed in a Galaxy workflow [44]. Dereplication, singleton removal, and clustering of sequences to operational taxonomic units (OTU, > 99\% similarity) were performed using BLAST Parser [45] implemented in a Galaxy workflow.

\subsection{Statistical analyses}

The multivariate analyses on the nematode and the nematode-associated microbial OTU abundances were carried out with the R software version R4.0.0 (R Core Development Team) using the packages vegan [46], labDSV [47], and in SAS 9.4 (SAS Institute Inc., Cary, NC, United States) using the GLIMIX procedure [48]. The effect of replanting on the shoot or root fresh masses measured for each sampling was analyzed by one-way analysis of variance (ANOVA) with Tukey's honestly significant difference (HSD) test. All statistical analyses were done on non-rarefied OTU data, but normalization of sequencing depth was based on relative abundances (i.e., sequence counts in each column were scaled by the column's sum). The relative abundances of the nematodes were calculated on the order level and the associated microbes at the phylum level. The effect of soil type or treatment on the relative abundances was evaluated using a multivariate analysis of variance (MANOVA) followed by two-way ANOVA with Tukey's HSD test. Diagnostic plots of residuals versus fitted values revealed the lack of significant heterogeneity of variance and Q-Q plots showed that assumptions of normality were justified. To test the effect of the treatment and the soil type on the nematode or the nematode-associated microbial communities, we fitted a Principal Component (PC) rotation test model using a SAS/IML script [49]. The squared multiple correlation coefficient $\mathrm{R}^{2}$ as effect measure can be interpreted as the proportion of variability in the observed similarity measures explained by 
the factor tested. LEfSe (Linear discriminant analysis Effect Size) was used to find differentially abundant OTU that best explain the differences between ARD and control plots in the community structures of nematodes and nematode-associated fungi and bacteria, respectively. The test first utilizes the non-parametric factorial Kruskal-Wallis (KW) sumrank test [50] to identify OTU with significant differential abundance; biological consistency is afterward examined using Wilcoxon rank-sum tests [51]. Finally, LEfSe uses linear discriminant analysis (LDA) to estimate the effect size of each differentially abundant OTU (LSD > 2.0) [52]. To investigate the relationship between the differentially abundant nematode and nematode-associated microbial OTU and the root weight of apple plants, we used canonical correspondence analysis (CCA). Root weight was only available for each plant of samplings H4 (Heidgraben April 2017) and E3 (Ellerhoop April 2018). CCA was carried out on the relative abundances of OTU at 999 permutations. The correlation of OTU to the reduced plant growth was calculated by the 'Envfit' function at 999 permutations [46].

\section{Results}

\subsection{Reduction in apple plant growth after repeated replanting}

Replanting apple in the same plots resulted in progressive growth reduction in both fields, Ellerhoop and Heidgraben (Figure 1). In Ellerhoop, plant growth was generally poor in the first period ending in the year 2010, probably due to unfavorable weather conditions. However, shoot fresh mass was significantly reduced when considering the following periods of replanting. An exponential decline in shoot weight was observed. In Heidgraben, plant growth was drastically decreased in the first replanting period 2011-2013 and decreased further in the second period 2013-2015.

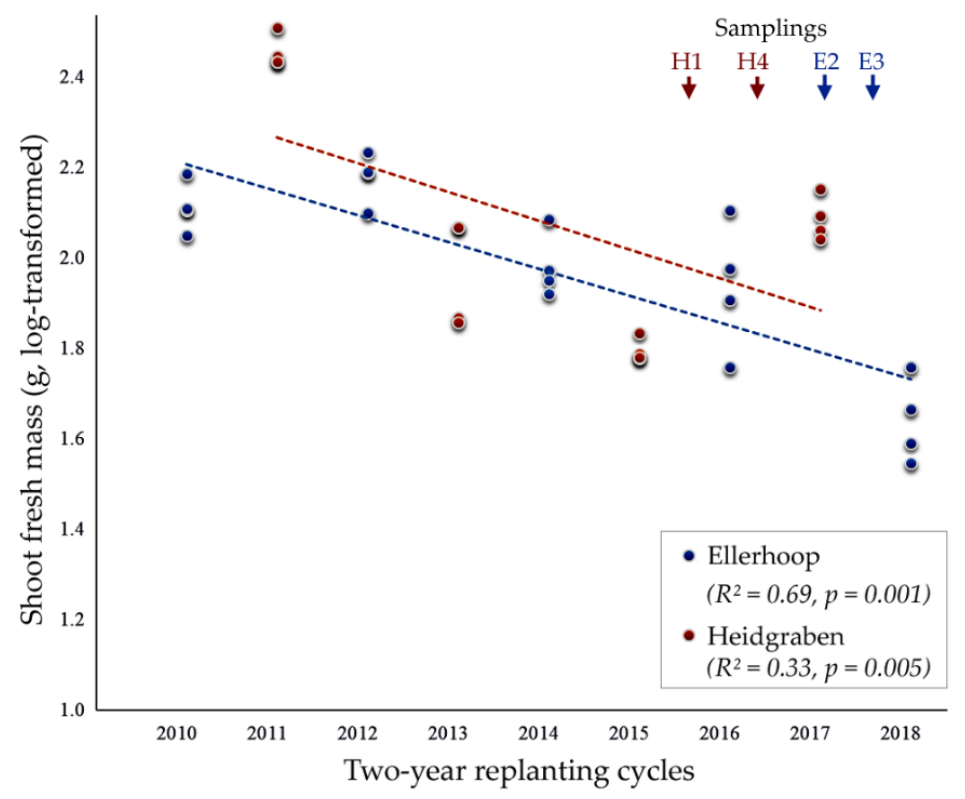

Figure 1. Reduction in shoot fresh mass of apple plants in the course of consecutive twoyear replanting cycles in the experimental fields near Ellerhoop and Heidgraben. Shoot mass was determined after uprooting at the end of each growth cycle.

Despite on average good growth conditions in the period 2015-2017, which was also obvious for the plants in the Ellerhoop field, shoot mass was significantly lower compared to the first period. Overall, the growth decline associated with the replanting of apple rootstocks was faster and more severe in the more sandy soil of the Heidgraben field compared to the Ellerhoop field. 
Root weight was measured for each plant of samplings H4 (Heidgraben April 2017) and E3 (Ellerhoop April 2018). Overall, the root weight was significantly reduced in replanted plots compared to plots that were first time planted with apple rootstocks (ANOVA, $F=21.9, P<0.001$ ). The effect was mostly attributed to E3 with a $72 \%$ reduction of root weight in ARD soil, while plants sampled at H4 from ARD plots were only reduced by $30 \%$ in root weight compared to plants grown in control plots (Supplementary Fig. S1).

\subsection{Nematode community structure in replanted and control plots}

Overall, high proportions of the orders Rhabditida and Tylenchida dominated the nematode communities, next to Triplonchida, Dorylaimida, Diplogasterida, Araeolaimida, Mononchida, and Chromadorida (Supplementary Fig. S2). The factors sampling and replanting significantly affected the relative abundance of most of these orders (Supplementary Table S1). On the level of OTU, replanting had a significant effect on the composition of the nematode community, when comparing replanted to control plots using a multivariate principal component test (Table 1). Nematode communities also differed significantly among samplings, reflecting the combined effects of soil type, site and year. However, replanting explained a greater proportion of the variance than the factor sampling, as indicated by a larger Pearson factor (Table 1). In principal component analysis, the second principal component clearly separated the nematode communities from replanted and control plots (Fig. 2). While for the Ellerhoop field the nematode communities remained stable at consecutive samplings in plots of the same treatment, the nematode community structure in the Heidgraben field shifted in direction of the second principal component. The first principal component separated the nematode communities from the two field sites.

Table 1. Multivariate tests on the effects of apple replanting on the nematode communities or nematode-associated microbes, with sampling (year/site) as confounding factor, using a number of principal components explaining $70 \%$ of the total variance.

\begin{tabular}{llcc}
\hline Taxonomic group & Fixed effect & Pearson factor & $P$-value \\
\hline Nematode community & Replanting (ARD/Healthy) & 0.75 & $<0.0001$ \\
& Sampling (H1/E2/E3/H4) & 0.56 & $<0.0001$ \\
\multirow{2}{*}{$\begin{array}{l}\text { Nematode-associated } \\
\text { fungi }\end{array}$} & Replanting (ARD/Healthy) & 0.56 & $<0.0001$ \\
Nematode-associated & Sampling (H1/E2/E3/H4) & 0.74 & $<0.0001$ \\
bacteria & Replanting (ARD/Healthy) & 0.52 & $<0.0001$ \\
& Sampling (H1/E2/E3/H4) & 0.55 & $<0.0001$ \\
\hline
\end{tabular}




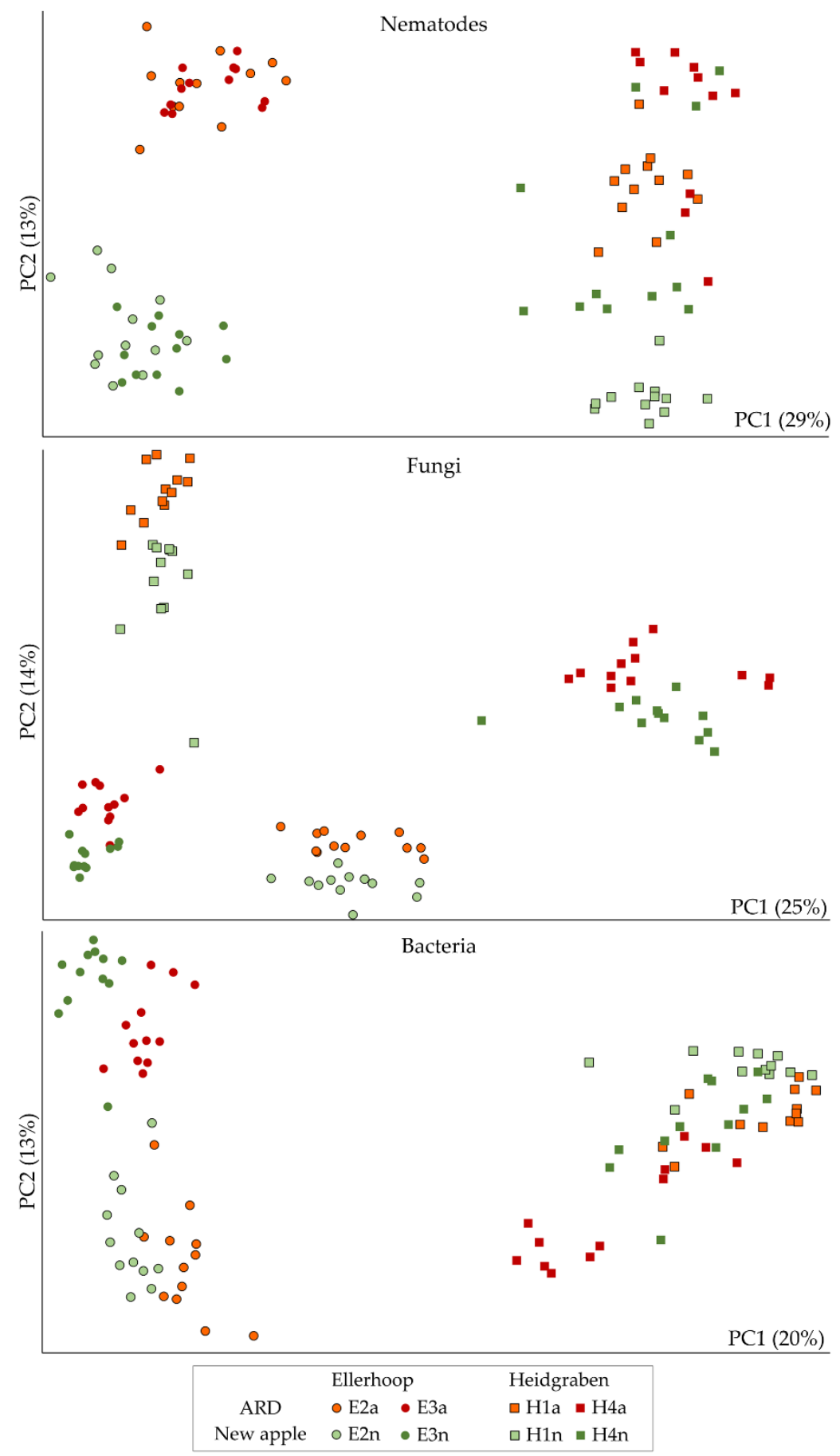

Figure 2. Principal component analyses of nematode communities and co-extracted fungal and bacterial microbiomes from replanted plots with apple replant disease (ARD, red/orange symbols) or control plots that were planted with apple for the first time after grass cover (new apple, green symbols). The field experiment of Ellerhoop was sampled in November 2017 (E2) and April 2018 (E3), the field experiment of Heidgraben was sampled in April 2016 (H1) and April 2017 (H4). The first two principal components (PC1, PC2, \% explained variance in brackets) of log-transformed relative abundances of OTU from high-throughput amplicon sequencing data of ribosomal markers are shown. 
Effect sizes of LDA determined by LefSe analysis revealed three nematode OTU that were strongly associated with replanted plots (Table 2). These were taxonomically assigned to the free-living genera Cephalenchus, Aphelenchus, and a member of the Dorilaimida with an $18 \mathrm{~S}$ rRNA sequence that has not yet been assigned to a known species. The bacterivorous nematode Rhabditis was strongly associated with the healthy control plots. The plant-ectoparasite Helicothylenchus was also associated with control plots, but less pronounced.

Table 2. Linear discriminant analysis (LDA) scores of differentially abundant nematode operational taxonomic units (OTU) that showed the highest association with apple replant diseased plots (negative scores) or control plots (positive scores) among all detected OTU, and their $18 S$ rRNA sequence similarity to nematodes in the SILVA database (version 138.1).

\begin{tabular}{cccc}
\hline OTU & LDA Score & SILVA BlastN hit & Identity \\
\hline 36 & -4.5 & AY284594 Cephalenchus hexalineatus & $100 \%$ \\
25 & -4.2 & AJ875139 Dorylaimida & $99.6 \%$ \\
2 & -4.2 & AB368918 Aphelenchus avenae & $100 \%$ \\
\hline 43 & 5.1 & AY284653 Rhabditis terricola & $100 \%$ \\
169 & 3.7 & KJ869398 Helicotylenchus digitiformis & $100 \%$ \\
\hline
\end{tabular}

\subsection{Nematode-associated fungi in replanted and control plots}

The taxonomic composition of the fungal communities that were associated with the extracted nematodes were dominated by high proportions of Ascomycota and Basidiomycota (Supplementary Figure S3). Mortierellomycota were overall more abundant for each sampling in the nematode fractions that were extracted from replanted plots compared to control plots, although their abundance largely varied among samples. Rozellomycota and Chytridiomycota were significantly associated with replanted plots (Supplementary Table S1). The multivariate principal component test revealed, that replanting had a significant effect on the relative abundances of nematode-associated fungal OTU (Table 1). The composition of fungal OTU differed significantly among samplings (Table 1). This effect was more pronounced than the effect of replanting as indicated by a higher Pearson factor. In principal component analysis, the second principal component separated the nematode-associated fungal communities from replanted and control plots, while this separation was not as sharp as observed for the nematode communities (Fig. 2).

Effect sizes of LDA determined by LefSe analysis identified Mortierella as significantly associated with the nematodes in replanted plots (Table 3). Less pronounced were associations with Cercophora, an unknown member of the Helotiales, and a species related to Pseudogymnoascus. Several OTU with similarity to species hypotheses of the UNITE database were indicative of control plots, mainly an unknown member of the family Chaetomiaceae with $100 \%$ sequence identity to species hypothesis SH1578257. With lower LDA scores, some nematode-associated fungal OTU related to the genera Cirrenalia, Bipolaris, Marasmius, and Metarhizium were also indicators of healthy control plots. 
Table 3. Linear discriminant analysis (LDA) scores of differentially abundant nematodeassociated fungal operational taxonomic units (OTU) that showed the highest association with replanted plots (negative scores) or control plots (positive scores) among all detected OTU, and their ITS sequence similarity to nematodes in the UNITE database (version 8.3).

\begin{tabular}{cccc}
\hline OTU & LDA Score & UNITE BlastN hit & Identity \\
\hline 3184 & -4.24 & SH1557087 Mortierella & $100 \%$ \\
4072 & -3.65 & SH1578257 Cercophora & $100 \%$ \\
3099 & -3.23 & SH2750281 Helotiales & $89.9 \%$ \\
4020 & -3.22 & SH1557243 Pseudogymnoascus & $97.5 \%$ \\
\hline 3218 & 4.73 & SH1615738 Chaetomiaceae & $100 \%$ \\
1653 & 3.70 & SH2732359 Cirrenalia & $100 \%$ \\
4491 & 3.59 & SH1657881 Bipolaris sorokiniana & $100 \%$ \\
1503 & 3.54 & SH2720643 Marasmius & $96.9 \%$ \\
804 & 3.36 & SH1561418 Metarhizium marquandii & $99.6 \%$ \\
\hline
\end{tabular}

\subsection{Nematode-associated bacteria in replanted and control plots}

The phylum composition of the bacterial communities associated with nematodes varied by the sampling and to a lesser extent by the treatment (Supplementary Table S1). High proportions of Proteobacteria, Bacteroidetes, and Actinobacteria dominated the nematode-associated bacterial communities. The composition of bacterial OTU that were co-extracted with the nematodes was significantly different between replanted and control plots (Table 1). Sampling (and thereby soil type/site/year) had a significant effect on the nematode-associated bacterial communities, which was more pronounced than the effect of replanting as indicated by a higher Pearson factor. In principal component analysis, the first principal component separated the nematode-associated bacterial communities of the two field sites (Fig. 2). In contrast to nematodes and fungi, the first and second principal component explained a lower percentage of the total variance, and the second principal component did not well reflect the difference in replanted and control plots.

Table 4. Linear discriminant analysis (LDA) scores of differentially abundant nematodeassociated bacterial operational taxonomic units (OTU) that showed the highest association with replanted plots (negative scores) or control plots (positive scores) among all detected OTU, and their 16S rRNA gene sequence similarity to bacteria in the SILVA database (version 138.1).

\begin{tabular}{cccc}
\hline OTU & LDA score & SILVA BlastN hit & Identity \\
\hline 269 & -3.08 & EU937916 Methylotenera & $98.7 \%$ \\
268 & -2.56 & KC172347 Methylophilus & $99.5 \%$ \\
324 & -2.42 & KX146487 Flavitalea antarctica & $100 \%$ \\
\hline 9262 & 3.11 & DQ125809 Streptomyces & $98.8 \%$ \\
38 & 2.94 & MW339074 Sphingomonas & $100 \%$ \\
284 & 2.89 & EF019722 Acidibacter & $98.5 \%$ \\
228 & 2.68 & JF120108 Luedemannella & $100 \%$ \\
1035 & 2.52 & GQ264163 Steroidobacter & $98.2 \%$ \\
2254 & 2.51 & JF176556 Chloroflexi & $99.5 \%$ \\
\hline
\end{tabular}


Lefse analysis pointed to the genera Methylotenera, Methylophilus, and Flavitalea as indicators of replanting, although with much smaller effect sizes than observed for nematode and fungi indicators (Table 4). OTU belonging to the genera Streptomyces, Sphingomonas, Acidibacter, or Luedemannella were most indicative of healthy control plots.

\subsection{CCA analysis of the associations of OTU abundance and root weight}

For the later samplings E3 and H4, root weight was determined, which presumably reflected the effect of ARD on plant growth and the heterogeneous distribution of the disease among plots (Supplementary Fig. S1). This gave the chance to examine the species vs. plant response relationship by CCA for these samplings. The analysis revealed that the nematode Cephalenchus hexalineatus ( $\left.\mathrm{R}^{2}=0.42, P<0.001\right)$, Aphelenchus avenae $\left(\mathrm{R}^{2}=0.22, P\right.$ $<0.001)$, and an unidentified Dorylaimida $\left(\mathrm{R}^{2}=0.29, P<0.001\right)$ were significantly associated with replanted plots at these two samplings. The co-extracted fungal genera Mortierella $\left(\mathrm{R}^{2}=0.30, P<0.001\right)$ and Pseudogymnoascus $\left(\mathrm{R}^{2}=0.30, P=0.038\right)$, and the nematode co-extracted bacteria Methylophilus $\left(\mathrm{R}^{2}=0.23, P=0.002\right)$, Methylotenera $\left(\mathrm{R}^{2}=0.24, P<0.001\right)$ and Flavitalea antarctica $\left(\mathrm{R}^{2}=0.25, P<0.001\right)$ were significantly more abundant in ARD soils and correlated significantly to root growth reduction. Thus, the results of CCA corresponded well with the results of the Lefse analyses over all samplings.

\section{Discussion}

Apple plants respond negatively to soils that have been repeatedly planted with apples. The yield decline is attributed to a yet unknown complex of soil biota [8]. Interactions of biological agents were proposed to cause ARD but the understanding of the interactions and their implication to the apple plant is deficient. Extracellular compounds released by fungi in the apple rhizosphere were shown to affect apple roots regardless of fungal colonization $[14,18]$. This gives evidence that biotic interactions in the rhizosphere of apple plants may lead to the external production of deleterious compounds, which trigger ARD but needs to be investigated thoroughly. In principle, activities of nematodes in the plant-associated soils can cause mechanical damage to the host, which later trigger the defense response of the plant [53,54]. The opening of wounds on plants can also ease the entrance of pathogenic microorganisms that leads to secondary infections and disease complexes [21,55]. Recently the involvement of nematodes living freely in soils and their associated microbes in ARD was reported [28]. The investigation of nematode communities and their associated microbial communities between ARD and healthy plots points to specific nematodes living freely and their body-associated fungi or bacteria that were associated with symptoms of ARD in all the field soils analyzed. This study also found that plant-parasitic nematodes, particularly P. penetrans were not involved in the induction of the disease thus confirming earlier reports that nematicides targeting this species failed to mitigate ARD [5]. Fungicide application to ARD soils resulted in improved plant growth and reduction of plant pathogenic fungi or oomycete complexes of Cylindrocarpon/Nectriaceae, Fusarium, Pythium, Phytophthora, or Rhizoctonia [5,56-58]. However, their presence and frequency largely varied among orchards [59-61], and the contribution of some of the species such as Pythium, Phytophthora, and Rhizoctonia were not confirmed as causal agents to ARD [62]. These previous studies presumed that ARD causal agents must invade the root, thereby excluding external chemical interference with biota in the rhizosphere. In contrast, the present study aimed to find nematodes and the nematode-associated microbes living freely in the plant-associated soil, which interact in a way that harms the roots of apple plants leading to the production of stress-induced compounds in the affected roots. 
Here, the decline in shoot fresh mass measured over replant generations was used as a marker for ARD induction in the reference field sites. Generally, severe growth reduction was observed in Ellerhoop and Heidgraben thus indicating that ARD was induced at the sites. The progress of the disease was however different for each site. At Ellerhoop, plant growth was generally poor in the first period ending in the year 2010, probably due to weather conditions such as periods of drought, strong frosts, or waterlogging, factors known to affect apple plant growth $[29,63]$. It however decreased drastically with each cycle of replanting, which is the peculiar characteristic of replant disease. In the sandy soil of the Heidgraben field, plant growth was drastically decreased in the first replanting period and decreased faster than in the loamy sand of the Ellerhoop field, which is in line with the observation of more severe ARD symptomes of apple plants in sandy soils compared to loamy soils [29].

In this study, the nematode species composition at higher taxonomic order has been shown to vary among different soils or samplings rather than among the treatment. This observation reflects previous studies on the seasonal distribution of nematodes in apple orchards [64,65]. The order Rhabditida, constituting free-living nematodes was in high abundance compared to Tylenchida, which consists of mainly plant-parasitic nematodes. These findings coincide with our previous studies where it was shown that the free-living nematodes were significantly more abundant in ARD soils than the plant-parasitic nematodes [28]. Besides, other studies observed high proportions of free-living nematodes that varied amongst orchards [66]. The order Tylenchida constitutes major plant-parasitic nematodes that contribute significantly to global crop losses [67]. The groups' role in the disease complex is subjective as their distribution in affected orchards is highly variable $[6,68]$. P. penetrans did not play a role in ARD of the investigated fields because it was low in abundance, it did not increase over time, and it did not correlate with reduced root weight observed in the ARD plots. This finding is supported by studies by Manici et al. [16], who could not recover any plant-parasitic nematode from the roots of symptomatic apple plants. Although Manici et al. [16] previously reported the presence of root-lesion nematodes in affected roots, the low frequency of these nematodes did not indicate any significant contribution to the growth reduction in apple trees.

Differences in nematode communities between ARD field plots and uncultivated grass plots were reported previously [28]. In this study, differences in species composition between ARD and healthy soils were shown irrespective of soil type or sampling time, in a way that confirms that the nematode communities associated with plants showing ARD symptoms may be truly unique and could be linked to the growth reduction observed in these soils. This was consistent when individual soils were compared as well and confirmed the minor effect of soil properties in the induction of ARD [30].

In E3 and H4 soils, plant growth was significantly higher in healthy than in replanted plots. Histological analysis carried out by one of the project partners on the fine roots of plants grown in the ARD soils showed noticeable indicators of the disease symptoms such as cell damages like necrosis, blackening, and black cell inclusions in contrast to healthy roots [4]. We searched for putative OTU of nematodes and nematode-associated fungi or bacteria that were differentially abundant in the ARD across all sampling regimes (E2, E3, $\mathrm{H} 1$, and H4). We found OTU closely related to the nematodes Aphelenchus avenae, Cephalenchus hexalineatus, and an unidentified Dorylaimida that were more abundant in ARD soils and correlated significantly with root growth reduction measured for soils E3 and $\mathrm{H} 4$ respectively. Aphelenchus is a fungivorous nematode, which can potentially control plant-pathogenic fungi and in rare cases reproduce on seedling roots, callus tissue, and moss [69]. Cephalenchus is mostly associated with woody plants and was reported to feed on root cells but is not regarded to cause plant damage [70,71]. Dorylaimida are commonly found in moist soils, especially around plant roots. Many of them are free-living nematodes feeding on bacteria and other microorganisms including soil fungi and algae [72]. Previous studies frequently found high abundances of bacterivorous nematodes, notably unidentified members of Rhabditidae, and Cephalenchus to be associated with peach or apple replanted soils [28,73]. 
Characterization of the microbial communities associated with the cuticle of nematodes has gained popularity over the years [74]. However, most studies focused on the microbes directly attached to the plant-parasitic nematodes in soils to understand the underlying mechanism of how microbes can antagonize these plant parasites [74,75]. There have been few studies of host-associated microbes on free-living nematodes but mostly focused on evolutionary and ecological studies [76-78]. In this study, the microbial fractions associated with the total nematode community have been characterized. OTU closely related to fungi species of the genera, Mortierella, Cercophora, Pseudogymnaoascus and unidentified Helotiales were associated with nematodes in ARD soils and correlated with reduced root weight. Notably, the genus Mortierella has been repeatedly linked with ARD soils from different orchards [79]. Species of Mortierella were reported to colonize apple roots, leading to the conclusion that they may be associated with the onset of ARD $[56,80]$. Members of the genus Mortierella produce metabolites with antifungal and antibacterial activity that may also affect root cells [81,82]. Recently, the genus was found to correlate negatively with shoot growth hence providing more evidence for their involvement in ARD [83]. In other cases, they are noted to antagonize plant-parasitic nematodes [84-87]. Whiles this fits our findings, some studies reported variable abundances of Mortierella in the root zone soils of apple trees that could not be linked to tree health or correlated negatively with the severity of ARD [62,79]. Some species of Pseudogymnoascus have been reported to cause death in animals and have been shown to produce cuticle-degrading subtilisin peptidases [88], which are used by nematode-trapping fungi to kill nematodes [89]. Species of Cercophora are reportedly found on dung and often produce antifungal metabolites that inhibit the growth of other fungi [90]. Their role in ARD may be linked to the production of deleterious compounds directed towards nematodes or fungi, which may induce a stress response in apple roots [57]. The order Helotiales contains some of plant pathogens that cause brown rot of stone fruits, lettuce drop, black spot of roses, and soft rot of onions [91]. They were recently detected as the most dominant endophytes in ARD-affected roots [57]. Their role in ARD needs to be investigated further.

Bacteria OTU assigned to the genera Methylotenera, Methylophilus, Flavitalea antarctica were more abundant in ARD soils and correlated to root growth reduction. Methylotenera, Methylophilus are both methanol consumers and frequently play a role in the denitrification process [92]. The genus Flavitalea was associated with the replant disease by negatively correlating with shoot growth in replanted soils [24].

In conclusion, our study showed that ARD soils differ in species composition compared to healthy soils. Although cause-effect relation with symptoms of ARD cannot be proven, our results indicate that specific nematodes living freely in soil with their bodyassociated fungi or bacteria synergistically interact to affect apple plant health. Efforts will be made in the future to test putative nematode-associated microbe complexes in biotests for the pathogenicity of apple plants. In addition, extracellular compounds produced as a result of nematode-microbe interactions will be examined. Exploring the underlying synergy between the nematodes and microbes will give further insights into the etiology of the disease.

Supplementary Materials: The following are available online at www.mdpi.com/xxx/s1, Figure S1: Root fresh mass affected by replanting, Figure S2-S4: Taxonomic profiles of soil communities, Table S1: Replanting effects on soil biota at order level.

Author Contributions: Conceptualization, H.H.; methodology, X.K., H.H.; validation, X.K., H.H.; formal analysis, X.K., J.M., H.H.; investigation, X.K., A.W.; resources, A.W., J.M.; writing-original draft preparation, X.K.; writing-review and editing, H.H., X.K., A.W., J.M.; visualization, X.K., H.H.; supervision, H.H.; project administration, H.H.; funding acquisition, H.H., A.W. All authors have read and agreed to the published version of the manuscript." 
Funding: This research was funded by the German Federal Ministry of Research and Education, grant number 031B0512B. The APC was funded by the Julius Kühn-Institute.

Data Availability Statement: All sequence data related to this study are available in the NCBI SRA database (Accession No. PRJNA749392).

Acknowledgments: We thank the BonaRes initiative and the ORDIAmur consortium for continuous support and discussions.

Conflicts of Interest: The authors declare no conflict of interest. The funders had no role in the design of the study; in the collection, analyses, or interpretation of data; in the writing of the manuscript, or in the decision to publish the results.

\section{References}

1. Gao, Q.; Meng, X.; Yu, H. Reason analysis and control methods of succession cropping obstacle. Shandong Agr. Sci. 2006, 3, 60-63.

2. Oostenbrink, M.; Hoestra, H. Nematode damage and "specific sickness" in Rosa, Malus and Laburnum. T. Pl.ziekten 1961, 67, 264-272.

3. Pitcher, R.S.; Way, D.W.; Savory, B.M. Specific replant diseases of apple and cherry and their control by soil fumigation. J. Hort. Sci. 1966, 41, 379-396, doi:10.1080/00221589.1966.11514184.

4. Grunewaldt-Stöcker, G.; Mahnkopp, F.; Popp, C.; Maiss, E.; Winkelmann, T. Diagnosis of apple replant disease (ARD): microscopic evidence of early symptoms in fine roots of different apple rootstock genotypes. Scientia Hortic. 2019, 243, 583-594, doi:10.1016/j.scienta.2018.09.014.

5. Mazzola, M. Elucidation of the microbial complex having a causal role in the development of apple replant disease in Washington. Phytopathology 1998, 88, 930-938, doi:10.1094/PHYTO.1998.88.9.930.

6. Mai, W.F.; Merwin, I.A.; Abawi, G.S. Diagnosis, etiology and management of replant disorders in New York cherry and apple orchards. Acta Hortic. 1994, 363, 33-42, doi:10.17660/ActaHortic.1994.363.5.

7. Mai, W.F.; Abawi, G.S. Controlling replant diseases of pome and stone fruits in Northeastern United States by preplant fumigation. Plant Dis. 1981, 65, 859-864.

8. Winkelmann, T.; Smalla, K.; Amelung, W.; Baab, G.; Grunewaldt-Stöcker, G.; Kanfra, X.; Meyhöfer, R.; Reim, S.; Schmitz, M.; Vetterlein, D.; et al. Apple replant disease: causes and mitigation strategies. Curr. Issues Mol. Biol. 2019, 30, 89-106, doi:10.21775/cimb.030.089.

9. Yim, B.; Smalla, K.; Winkelmann, T. Evaluation of apple replant problems based on different soil disinfection treatments - links to soil microbial community structure? Plant Soil 2013, 366, 617-631, doi:10.1007/s11104-0121454-6.

10. Manici, L.M.; Kelderer, M.; Caputo, F.; Saccà, M.L.; Nicoletti, F.; Topp, A.R.; Mazzola, M. Involvement of Dactylonectria and Ilyonectria spp. in tree decline affecting multi-generation apple orchards. Plant Soil 2018, 425, 217-230, doi:10.1007/s11104-018-3571-3.

11. Weiß, S.; Liu, B.; Reckwell, D.; Beerhues, L.; Winkelmann, T. Impaired defense reactions in apple replant diseaseaffected roots of Malus domestica 'M26'. Tree Physiol. 2017, 37, 1-14, doi:10.1093/treephys/tpx108.

12. Weiß, S.; Bartsch, M.; Winkelmann, T. Transcriptomic analysis of molecular responses in Malus domestica 'M26' roots affected by apple replant disease. Plant Mol. Biol. 2017, 94, 303-318, doi:10.1007/s11103-017-0608-6.

13. Tewoldemedhin, Y.T.; Mazzola, M.; Labuschagne, I.; McLeod, A. A multi-phasic approach reveals that apple replant disease is caused by multiple biological agents, with some agents acting synergistically. Soil Biol. Biochem. 2011, 43, 1917-1927, doi:10.1016/j.soilbio.2011.05.014.

14. Manici, L.M.; Caputo, F.; Saccà, M.L. Secondary metabolites released into the rhizosphere by Fusarium oxysporum and Fusarium spp. as underestimated component of nonspecific replant disease. Plant Soil 2017, 415, 85-98, doi:10.1007/s11104-016-3152-2.

15. Otto, G. Investigations on the cause of soil sickness in fruit trees VII. An actinomycete isolated from rootlets of apple seedlings, the probable cause of specific apple replant disease. Journal of Cultivated Plants 2017, 69, 175-179, doi:10.1399/JfK.2017.05.04.

16. Manici, L.M.; Kelderer, M.; Franke-Whittle, I.H.; Rühmer, T.; Baab, G.; Nicoletti, F.; Caputo, F.; Topp, A.; Insam, H.; Naef, A.; et al. Relationship between root-endophytic microbial communities and replant disease in specialized apple growing areas in Europe. Appl. Soil Ecol. 2013, 72, 207-214, doi:10.1016/j.apsoil.2013.07.011. 
17. Nicola, L.; Insam, H.; Pertot, I.; Stres, B. Reanalysis of microbiomes in soils affected by apple replant disease (ARD): old foes and novel suspects lead to the proposal of extended model of disease development. Appl. Soil Ecol. 2018, 129, 24-33, doi:10.1016/j.apsoil.2018.04.010.

18. Manici, L.M.; Caboni, E.; Caputo, F.; Frattarelli, A.; Lucioli, S. Phytotoxins from Dactylonectria torresensis involved in replant disease of fruit trees. Rhizosphere 2021, 17, 100300, doi:10.1016/j.rhisph.2020.100300.

19. Dillman, A.R.; Chaston, J.M.; Adams, B.J.; Ciche, T.A.; Goodrich-Blair, H.; Stock, S.P.; Sternberg, P.W. An entomopathogenic nematode by any other name. PLoS Pathog. 2012, 8, e1002527, doi:10.1371/journal.ppat.1002527.

20. Allen, J. Annual ryegrass toxicity - an animal disease caused by toxins produced by a bacterial plant pathogen. Microbiol. Aust. 2012, 33, 18, doi:10.1071/MA12018.

21. Back, M.A.; Haydock, P.P.J.; Jenkinson, P. Disease complexes involving plant parasitic nematodes and soilborne pathogens. Plant Pathol. 2002, 51, 683-697, doi:10.1046/j.1365-3059.2002.00785.x.

22. Morris, K.A.; Langston, D.B.; Dutta, B.; Davis, R.F.; Timper, P.; Noe, J.P.; Dickson, D.W. Evidence for a disease complex between Pythium aphanidermatum and root-knot nematodes in cucumber. Plant Health Progr. 2016, 17, 200-201, doi:10.1094/PHP-BR-16-0036.

23. Yim, B.; Winkelmann, T.; Ding, G.-C.; Smalla, K. Different bacterial communities in heat and gamma irradiation treated replant disease soils revealed by $16 \mathrm{~S}$ rRNA gene analysis - contribution to improved aboveground apple plant growth? Front. Microbiol. 2015, 6, 1224, doi:10.3389/fmicb.2015.01224.

24. Yim, B.; Nitt, H.; Wrede, A.; Jacquiod, S.; Sørensen, S.J.; Winkelmann, T.; Smalla, K. Effects of soil pre-treatment with Basamid® granules, Brassica juncea, Raphanus sativus, and Tagetes patula on bacterial and fungal communities at two apple replant disease sites. Front. Microbiol. 2017, 8, 1604, doi:10.3389/fmicb.2017.01604.

25. Kanfra, X.; Obawolu, T.; Wrede, A.; Strolka, B.; Winkelmann, T.; Hardeweg, B.; Heuer, H. Alleviation of Nematode-Mediated Apple Replant Disease by Pre-Cultivation of Tagetes. Horticulturae 2021, 7, 433, doi:10.3390/horticulturae7110433.

26. Johnson, P.W.; Dirks, V.A.; Pree, D.J.; Marks, C.F. Systemic nematicides for control of Pratylenchus penetrans during apple orchard estabishment in Ontario. Plant Dis. 1982, 66, 299-301.

27. Jaffee, B.A.; Abawi, G.S.; Mai, W.F. Role of soil microflora and Pratylenchus penetrans in an apple replant disease. Phytopathology 1982, 72, 247-251.

28. Kanfra, X.; Liu, B.; Beerhues, L.; Sørensen, S.J.; Heuer, H. Free-living nematodes together with associated microbes play an essential role in apple replant disease. Front. Plant Sci. 2018, 9, 1666, doi:10.3389/fpls.2018.01666.

29. Mahnkopp, F.; Simon, M.; Lehndorff, E.; Pätzold, S.; Wrede, A.; Winkelmann, T. Induction and diagnosis of apple replant disease (ARD): a matter of heterogeneous soil properties? Scientia Hortic. 2018, 241, 167-177, doi:10.1016/j.scienta.2018.06.076.

30. Simon, M.; Lehndorff, E.; Wrede, A.; Amelung, W. In-field heterogeneity of apple replant disease: Relations to abiotic soil properties. Scientia Hortic. 2020, 259, 108809, doi:10.1016/j.scienta.2019.108809.

31. Lucas, M.; Balbín-Suárez, A.; Smalla, K.; Vetterlein, D. Root growth, function and rhizosphere microbiome analyses show local rather than systemic effects in apple plant response to replant disease soil. PLoS One 2018, 13, e0204922, doi:10.1371/journal.pone.0204922.

32. Reim, S.; Rohr, A.-D.; Winkelmann, T.; Weiß, S.; Liu, B.; Beerhues, L.; Schmitz, M.; Hanke, M.-V.; Flachowsky, H. Genes involved in stress response and especially in phytoalexin biosynthesis are upregulated in four Malus genotypes in response to apple replant disease. Front. Plant Sci. 2020, 10, 1724, doi:10.3389/fpls.2019.01724.

33. Hooper, D.J.; Hallmann, J.; Subbotin, S.A. Methods for extraction, processing and detection of plant and soil nematodes. In Plant parasitic nematodes in subtropical and tropical agriculture, 2nd; Luc, M., Sikora, R.A., Bridge, J., Eds.; CABI: Wallingford, 2005; pp 53-85, ISBN 9780851997278.

34. Kaplan, D.T.; Thomas, W.K.; Frisse, L.M.; Sarah, J.-L.; Stanton, J.M.; Speijer, P.R.; Marin, D.H.; Opperman, C.H. Phylogenetic analysis of geographically diverse Radopholus similis via rDNA sequence reveals a monomorphic motif. J. Nematol. 2000, 32, 134.

35. Porazinska, D.L.; Giblin-Davis, R.M.; Faller, L.; Farmerie, W.; Kanzaki, N.; Morris, K.; Powers, T.O.; Tucker, A.E.; Sung, W.; Thomas, W.K. Evaluating high-throughput sequencing as a method for metagenomic analysis of nematode diversity. Mol. Ecol. Resour. 2009, 9, 1439-1450, doi:10.1111/j.1755-0998.2009.02611.x.

36. Moll, J.; Roy, F.; Bässler, C.; Heilmann-Clausen, J.; Hofrichter, M.; Kellner, H.; Krabel, D.; Schmidt, J.H.; Buscot, F.; Hoppe, B. First Evidence That Nematode Communities in Deadwood Are Related to Tree Species Identity and to Co-Occurring Fungi and Prokaryotes. Microorganisms 2021, 9, 1454, doi:10.3390/microorganisms9071454.

37. Ihrmark, K.; Bödeker, I.T.M.; Cruz-Martinez, K.; Friberg, H.; Kubartova, A.; Schenck, J.; Strid, Y.; Stenlid, J.; Brandström-Durling, M.; Clemmensen, K.E.; et al. New primers to amplify the fungal ITS2 region--evaluation by 
454-sequencing of artificial and natural communities. FEMS Microbiol. Ecol. 2012, 82, 666-677, doi:10.1111/j.15746941.2012.01437.x.

38. Sundberg, C.; Al-Soud, W.A.; Larsson, M.; Alm, E.; Yekta, S.S.; Svensson, B.H.; Sørensen, S.J.; Karlsson, A. 454 pyrosequencing analyses of bacterial and archaeal richness in 21 full-scale biogas digesters. FEMS Microbiol. Ecol. 2013, 85, 612-626, doi:10.1111/1574-6941.12148.

39. Caporaso, J.G.; Lauber, C.L.; Walters, W.A.; Berg-Lyons, D.; Lozupone, C.A.; Turnbaugh, P.J.; Fierer, N.; Knight, R. Global patterns of $16 \mathrm{~S}$ rRNA diversity at a depth of millions of sequences per sample. Proc. Natl. Acad. Sci. U. S. A. 2011, 108 Suppl 1, 4516-4522, doi:10.1073/pnas.1000080107.

40. Edgar, R.C. UPARSE: highly accurate OTU sequences from microbial amplicon reads. Nature Methods 2013, 10, 996-998.

41. Quast, C.; Pruesse, E.; Yilmaz, P.; Gerken, J.; Schweer, T.; Yarza, P.; Peplies, J.; Glöckner, F.O. The SILVA ribosomal RNA gene database project: Improved data processing and web-based tools. Nucleic Acids Res. 2013, 41, D590-6, doi:10.1093/nar/gks1219.

42. Masella, A.P.; Bartram, A.K.; Truszkowski, J.M.; Brown, D.G.; Neufeld, J.D. PANDAseq: Paired-end assembler for illumina sequences. BMC Bioinform. 2012, 13, 31, doi:10.1186/1471-2105-13-31.

43. Abarenkov, K.; Zirk, A.; Piirmann, T.; Pöhönen, R.; Ivanov, F.; Nilsson, R.H.; Kõljalg, U. UNITE general FASTA release for Fungi, 2021, doi:10.15156/BIO/1280049.

44. Cock, P.J.A.; Grüning, B.A.; Paszkiewicz, K.; Pritchard, L. Galaxy tools and workflows for sequence analysis with applications in molecular plant pathology. PeerJ 2013, 1, e167, doi:10.7717/peerj.167.

45. Antweiler, K.; Schreiter, S.; Keilwagen, J.; Baldrian, P.; Kropf, S.; Smalla, K.; Grosch, R.; Heuer, H. Statistical test for tolerability of effects of an antifungal biocontrol strain on fungal communities in three arable soils. Microb. Biotechnol. 2017, 10, 434-449, doi:10.1111/1751-7915.12595.

46. Oksanen, J.; Blanchet, F.G.; Kindt, R.; Legendre, P.; Minchin, P.R.; O’hara, R.B.; Simpson, G.L.; Solymos, P.; Stevens, M.H.H.; Wagner, H. vegan: Community Ecology Package. R package version 2.3-0. 2015. Available online: https://cran.r-project.org/web/packages/vegan.

47. Roberts, D.W. labdsv: Ordination and multivariate analysis for ecology. Available online: https://cran.r-project.org/web/packages/labdsv/labdsv.pdf (accessed on 23 July 2018).

48. Hierarchical logistic regression modeling with SAS GLIMMIX. Proceedings of the thirty-first annual SAS users group international conference. Cary, North Carolina: SAS Institute Inc; Citeseer, 2006.

49. Ding, G.-C.; Smalla, K.; Heuer, H.; Kropf, S. A new proposal for a principal component-based test for high-dimensional data applied to the analysis of PhyloChip data. Biom. J. 2012, 54, 94-107, doi:10.1002/bimj.201000164.

50. Kruskal, W.H.; Wallis, W.A. Use of ranks in one-criterion variance analysis. Journal of the American statistical Association 1952, 47, 583-621.

51. Wilcoxon, F. Individual Comparisons by Ranking Methods. Biometrics Bulletin 1945, 1, 80, doi:10.2307/3001968.

52. Fisher, R.A. The use of multiple measurements in taxonomic problems. Annals of eugenics 1936, 7, 179-188.

53. Holbein, J.; Grundler, F.M.W.; Siddique, S. Plant basal resistance to nematodes: an update. J. Exp. Bot. 2016, 67, 2049-2061, doi:10.1093/jxb/erw005.

54. Shah, S.J.; Anjam, M.S.; Mendy, B.; Anwer, M.A.; Habash, S.S.; Lozano-Torres, J.L.; Grundler, F.M.W.; Siddique, $\mathrm{S}$. Damage-associated responses of the host contribute to defence against cyst nematodes but not root-knot nematodes. J. Exp. Bot. 2017, 68, 5949-5960, doi:10.1093/jxb/erx374.

55. Karimi, M.; van Montagu, M.; Gheysen, G. Nematodes as vectors to introduce Agrobacterium into plant roots. Mol. Plant Pathol. 2000, 1, 383-387, doi:10.1046/j.1364-3703.2000.00043.x.

56. Mazzola, M.; Manici, L.M. Apple replant disease: role of microbial ecology in cause and control. Annu. Rev. Phytopathol. 2012, 50, 45-65, doi:10.1146/annurev-phyto-081211-173005.

57. Popp, C. Investigations on the occurrence of fungal root endophytes and an associated mycovirus in context with apple replant disease. PhD Thesis; Leibniz Universität Hannover, Hannover, 2020.

58. Popp, C.; Grunewaldt-Stöcker, G.; Maiss, E. A soil-free method for assessing pathogenicity of fungal isolates from apple roots. J. Plant Dis. Prot. 2019, 101, 15, doi:10.1007/s41348-019-00236-6.

59. Tewoldemedhin, Y.T.; Mazzola, M.; Mostert, L.; McLeod, A. Cylindrocarpon species associated with apple tree roots in South Africa and their quantification using real-time PCR. Eur. J. Plant Pathol. 2011, 129, 637-651, doi:10.1007/s10658-010-9728-4.

60. Tewoldemedhin, Y.T.; Mazzola, M.; Botha, W.J.; Spies, C.F.J.; McLeod, A. Characterization of fungi (Fusarium and Rhizoctonia) and oomycetes (Phytophthora and Pythium) associated with apple orchards in South Africa. Eur. J. Plant Pathol. 2011, 130, 215-229, doi:10.1007/s10658-011-9747-9. 
61. Sun, J.; Zhang, Q.; Li, X.; Zhou, B.; Wei, Q. Apple replant disorder of Pingyitiancha rootstock is closely associated with rhizosphere fungal community development. J. Phytopathol. 2017, 165, 162-173, doi:10.1111/jph.12547.

62. Wang, G.; Yin, C.; Pan, F.; WANG, X.; Xiang, L.; Wang, Y.; WANG, J.; TIAN, C.; CHEN, J.; Mao, Z. Analysis of the fungal community in apple replanted soil around Bohai Gulf. Hortic. Plant J. 2018, 4, 175-181, doi:10.1016/j.hpj.2018.05.003.

63. Mazzola, M.; Hewavitharana, S.S.; Strauss, S.L. Brassica seed meal soil amendments transform the rhizosphere microbiome and improve apple production through resistance to pathogen reinfestation. Phytopathology 2015, 105, 460-469, doi:10.1094/PHYTO-09-14-0247-R.

64. Costante, J.F.; Mai, W.F.; Aleong, J.; Klein, R.M. Effects of apple rootstocks and nematicides on Pratylenchus penetrans populations and apple tree growth. J. Am. Soc. Hortic. Sci. 1987, 112, 441-444.

65. Kotcon, J.B. Distribution, frequency, and population density of nematodes in West Virginia peach orchards. J. Nematol. 1990, 22, 712-717.

66. Isutsa, D.K.; Merwin, I.A. Nematodes and fungi associated with apple replant disorder in sampled New York State orchards. Global J. Bioscience Biotechnol. 2014, 3, 174-180.

67. Singh, S.; Singh, B.; Singh, A.P. Nematodes: a threat to sustainability of agriculture. Procedia Environ. Sci. 2015, 29, 215-216, doi:10.1016/j.proenv.2015.07.270.

68. Hoestra, H.; Oostenbrink, M. Nematodes in relation to plant growth. IV. Pratylenchus penetrans (Cobb) on orchard trees. Neth. J. Agric. Sci. 1962, 10, 286-296.

69. Haraguchi, S.; Yoshiga, T. Potential of the fungal feeding nematode Aphelenchus avenae to control fungi and the plant parasitic nematode Ditylenchus destructor associated with garlic. Biol. Control 2020, 143, 104203.

70. Sutherland, J.R. Parasitism of Tylenchus emarginatus on conifer seedling roots and some observations on the biology of the nematode. Nematologica 1967, 13, 191-196, doi:10.1163/187529267X00049.

71. Siddiqi, M.R. Tylenchida: parasites of plants and insects; CABI: Wallingford, 2000, ISBN 9780851992020.

72. Jairajpuri, M.S.; Ahmad, W. Dorylaimida: free-living, predaceous and plant-parasitic nematodes; Brill, 1992, ISBN 9004092293.

73. Pokharel, R.R.; Reighard, G.L. Evaluation of biofumigation, soil solarization and rootstock on peach replant disease. Acta Hortic. 2015, 1084, 577-584, doi:10.17660/ActaHortic.2015.1084.78.

74. Elhady, A.; Giné, A.; Topalović, O.; Jacquiod, S.; Sørensen, S.J.; Sorribas, F.J.; Heuer, H. Microbiomes associated with infective stages of root-knot and lesion nematodes in soil. PLoS One 2017, 12, e0177145, doi:10.1371/journal.pone.0177145.

75. Topalović, O.; Bredenbruch, S.; Schleker, A.S.S.; Heuer, H. Microbes attaching to endoparasitic phytonematodes in soil trigger plant defense upon root penetration by the nematode. Front. Plant Sci. 2020, 11, 138, doi:10.3389/fpls.2020.00138.

76. Derycke, S.; Meester, N. de; Rigaux, A.; Creer, S.; Bik, H.; Thomas, W.K.; Moens, T. Coexisting cryptic species of the Litoditis marina complex (Nematoda) show differential resource use and have distinct microbiomes with high intraspecific variability. Mol. Ecol. 2016, 25, 2093-2110, doi:10.1111/mec.13597.

77. Dirksen, P.; Marsh, S.A.; Braker, I.; Heitland, N.; Wagner, S.; Nakad, R.; Mader, S.; Petersen, C.; Kowallik, V.; Rosenstiel, P.; et al. The native microbiome of the nematode Caenorhabditis elegans: gateway to a new host-microbiome model. BMC Biol. 2016, 14, 38, doi:10.1186/s12915-016-0258-1.

78. Schuelke, T.; Pereira, T.J.; Hardy, S.M.; Bik, H.M. Nematode-associated microbial taxa do not correlate with host phylogeny, geographic region or feeding morphology in marine sediment habitats. Mol. Ecol. 2018, 27, 1930-1951, doi:10.1111/mec.14539.

79. Bintarti, A.F.; Wilson, J.K.; Quintanilla-Tornel, M.A.; Shade, A. Biogeography and diversity of multi-trophic root zone microbiomes in Michigan apple orchards: analysis of rootstock, scion, and local growing region. Phytobiomes J. 2020, 4, 122-132, doi:10.1094/PBIOMES-01-20-0007-R.

80. Utkhede, R.S.; Li, T.S.C. Chemical and biological treatments for control of apple replant disease in British Columbia. Can. J. Plant Pathol. 1989, 11, 143-147.

81. Soman, A.G.; Gloer, J.B.; Wicklow, D.T. Antifungal and antibacterial metabolites from a sclerotium-colonizing isolate of Mortierella vinacea. J. Nat. Prod. 1999, 62, 386-388, doi:10.1021/np980411h.

82. Deacon, L.J.; Pryce-Miller, E.J.; Frankland, J.C.; Bainbridge, B.W.; Moore, P.D.; Robinson, C.H. Diversity and function of decomposer fungi from a grassland soil. Soil Biol. Biochem. 2006, 38, 7-20.

83. Nicola, L.; Turco, E.; Albanese, D.; Donati, C.; Thalheimer, M.; Pindo, M.; Insam, H.; Cavalieri, D.; Pertot, I. Fumigation with dazomet modifies soil microbiota in apple orchards affected by replant disease. Appl. Soil Ecol. 2017, 113, 71-79, doi:10.1016/j.apsoil.2017.02.002. 
84. Orion, D.; Kritzman, G. A role of the gelatinous matrix in the resistance of root-knot nematode (Meloidogyne spp.) eggs to microorganisms. J. Nematol. 2001, 33, 203.

85. Chen, S.Y.; Chen, F.J. Fungal parasitism of Heterodera glycines eggs as influenced by egg age and pre-colonization of cysts by other fungi. J. Nematol. 2003, 35, 271-277.

86. DiLegge, M.J.; Manter, D.K.; Vivanco, J.M. A novel approach to determine generalist nematophagous microbes reveals Mortierella globalpina as a new biocontrol agent against Meloidogyne spp. nematodes. Sci. Rep. 2019, 9, 7521, doi:10.1038/s41598-019-44010-y.

87. Haj Nuaima, R.; Ashrafi, S.; Maier, W.; Heuer, H. Fungi isolated from cysts of the beet cyst nematode parasitized its eggs and counterbalanced root damages. J. Pest Sci. 2021, 94, 563-572, doi:10.1007/s10340-020-01254-2.

88. O'Donoghue, A.J.; Knudsen, G.M.; Beekman, C.; Perry, J.A.; Johnson, A.D.; DeRisi, J.L.; Craik, C.S.; Bennett, R.J. Destructin-1 is a collagen-degrading endopeptidase secreted by Pseudogymnoascus destructans, the causative agent of white-nose syndrome. Proc. Natl. Acad. Sci. U.S.A. 2015, 112, 7478-7483, doi:10.1073/pnas.1507082112.

89. Yang, J.; Liang, L.; Zhang, Y.; Li, J.; Zhang, L.; Ye, F.; Gan, Z.; Zhang, K.-Q. Purification and cloning of a novel serine protease from the nematode-trapping fungus Dactylellina varietas and its potential roles in infection against nematodes. Appl. Microbiol. Biotechnol. 2007, 75, 557-565.

90. Wicklow, D.T.; Hirschfield, B.J. Evidence of a competitive hierarchy among coprophilous fungal populations. Can. J. Microbiol. 1979, 25, 855-858.

91. Horst, R.K. Plant diseases and their pathogens. Westcott's Plant Disease Handbook 1990, 86-515.

92. Beck, D.A.C.; Hendrickson, E.L.; Vorobev, A.; Wang, T.; Lim, S.; Kalyuzhnaya, M.G.; Lidstrom, M.E.; Hackett, M.; Chistoserdova, L. An integrated proteomics/transcriptomics approach points to oxygen as the main electron sink for methanol metabolism in Methylotenera mobilis. J. Bacteriol. 2011, 193, 4758-4765. 